\title{
Exploring the Self-Assembly and Energy Transfer of Dynamic Supramolecular Iridium-Porphyrin Systems
}

Diego Rota Martir, ${ }^{a}$ Gordon J. Hedley, ${ }^{b}$ David B. Cordes, ${ }^{a}$ Alexandra M. Z. Slawin, ${ }^{a}$ Daniel Escudero, ${ }^{c}$ Denis Jacquemin, ${ }^{c, d}$ Tamara Kosikova, ${ }^{a}$ Douglas Philp,, Daniel M. Dawson, Sharon E. Ashbrook, ${ }^{e}$ Ifor D.W. Samuel, ${ }^{b}$ and Eli Zysman-Colman ${ }^{a *}$

${ }^{a}$ Organic Semiconductor Centre, EaStCHEM School of Chemistry, University of St Andrews, St Andrews, Fife, KY16 9ST, UK, Fax: +44-1334 463808; Tel: +44-1334 463826; E-mail: eli.zysman-colman@st-andrews.ac.uk;

URL: http://www.zysman-colman.com

${ }^{b}$ Organic Semiconductor Centre, SUPA, School of Physics and Astronomy, University of St Andrews, St Andrews, Fife, KY16 9SS, UK

${ }^{c}$ CEISAM UMR CNRS 6230, Université de Nantes, 2 rue de la Houssinière, BP 92208 , 44322 Nantes Cedex 3, France

${ }^{d}$ Institut Universitaire de France, 1, rue Descartes, 75231 Paris Cedex 5, France

${ }^{e}$ EaStCHEM School of Chemistry and the Centre for Magnetic Resonance, University of St Andrews, North Haugh, St Andrews, Fife, KY16 9ST, UK

Abstract. We present the first examples of dynamic supramolecular systems composed of cyclometalated $\operatorname{Ir}(\mathrm{III})$ complexes of the form of $\left[\operatorname{Ir}\left(\mathrm{C}^{\wedge} \mathrm{N}\right)_{2}\left(\mathrm{~N}^{\wedge} \mathrm{N}\right)\right] \mathrm{PF}_{6}\left(\right.$ where $\mathrm{C}^{\wedge} \mathrm{N}$ is mesppy $=$ 2-phenyl-4-mesitylpyridinato and dFmesppy = 2-(4,6-difluorophenyl)-4-mesitylpyridinato and $\mathrm{N}^{\wedge} \mathrm{N}$ is $4,4^{\prime}: 2^{\prime}, 2^{\prime \prime}: 4^{\prime \prime}, 4^{\prime \prime}$-quaterpyridine, qpy) and zinc tetraphenylporphyrin (ZnTPP), assembled through non-covalent interactions between the distal pyridine moieties of the qpy ligand located on the iridium complex and the zinc of the ZnTPP. The assemblies have been comprehensively characterized by a series of analytical techniques ( ${ }^{1} \mathrm{H}$ NMR titration experiments, 2D COSY and HETCOR NMR spectra and low temperature ${ }^{1} \mathrm{H}$ NMR spectroscopy) and the crystal structures have been elucidated by X-ray diffraction. The optoelectronic properties of the assemblies and the electronic interaction between the iridium and porphyrin chromophoric units have been explored with detailed photophysical 
measurements, supported by time-dependent density functional theory (TD-DFT) calculations.

\section{Introduction.}

The efficient energy transfer exhibited by natural photosynthetic organisms through light-harvesting antennae has drawn tremendous interest over the last decades, not only for understanding the natural processes ${ }^{1}$ but also for technological applications in solar energy conversion, ${ }^{1 \mathrm{c}, 1 \mathrm{~d}, 2}$ which remains one of the great challenges of the century. ${ }^{2-3}$ In nature, lightharvesting antennae are composed of different chromophoric units, ${ }^{1 \mathrm{a}, 4}$ which are generally linked through non-covalent interactions ${ }^{5}$ such as hydrogen bonding, salt bridges, metalligand coordination or hydrophobic interactions, and are capable of absorbing sunlight and efficiently channeling the energy to the reaction center.

Much effort has been devoted to the preparation of artificial donor-acceptor systems based on combinations of multi-chromophoric arrays ${ }^{6}$ in order to emulate light harvesting in plants. In particular, the covalent association between photophysically-active $\mathrm{Ru}$ complexes and zinc-porphyrins has been well-explored in the context of understanding the efficiency of the energy transfer involved. ${ }^{7}$ In these systems, formation of a charge-separated state following ultra-fast photoinduced electron transfer (PeT) from the porphyrin donor to the ruthenium acceptor are generally observed and as a result, the phosphorescence of the ruthenium complexes is quenched and only weak porphyrin-centered luminescence is detected. $^{5 \mathrm{~b}, 6 \mathrm{f}}$

There are only a few examples of multi-metallic dyads and triads composed of metallo-porphyrins covalently linked to iridium(III) polypyridyl complexes. Unlike the 
examples discussed above, the nature of the electronic communication between the two chromophores is far from straightforward. For instance, Soliman and co-workers explored the energy transfer processes in a multi-metallic [ZnTAP]-[Pt]-[Ir] triad where $[\mathrm{ZnTAP}]$ is zinc tetraarylporphyrin $(\mathrm{ZnTAP}),[\mathrm{Pt}]$ is a $\mathrm{Pt}(\mathrm{II})$-diacetylide bridge and $[\operatorname{Ir}]$ is $\left[\operatorname{Ir}(\mathrm{ppy})_{2}(\mathrm{bpy})\right] \mathrm{PF}_{6}$ (ppyH $=2$-phenylpyridine; bpy $=2,2^{\prime}$-bipyridyl). Surprisingly, despite the presence of the trans-Pt(II)-diacetylide bridge that was expected to mediate a direct electronic communication between the two peripheral chromophores without itself contributing to the overall photo-processeses, ${ }^{8}$ no electronic communication between the two units was observed for this system. On the other hand, Sauvage, Flamigni and co-workers showed that in a triad consisting of zinc and gold tetraarylporphyrins covalently linked to a central bis(terpyridyl)iridium(III) complex [Ir] (schematically, [ZnTAP]-[Ir]-[AuTAP], where [AuTAP] is a gold tetraarylporphyrin), efficient and ultrafast electron transfer $\left(\mathrm{k}_{\mathrm{PeT}}>5 \times 10^{10}\right.$ $s^{-1}$ ) to the [AuTAP] occurred upon excitation of either [Ir] or [ZnTAP], leading to the formation of a long-lived charge-separated state $[\mathrm{ZnTAP}]^{+}-[\mathrm{Ir}]-[\mathrm{AuTAP}]^{--}$. No energy transfer was detected for this system. ${ }^{6 \mathrm{~d}}$

As these examples attest, although covalently linked metallo-porphyrin and chromophoric organometallic complex dyads and triads have been explored, ${ }^{6 \mathrm{~d},}$ 8-9 supramolecular systems involving metalloporphyrins and photophysically-active complexes non-covalently assembled remain largely unexplored. ${ }^{5 b, 10}$ One relevant example, reported by Kim and Shin, is that of an electron donor-acceptor dyad consisting of zinc tetratolylporphyrin (ZnTTP) and a tris(bipyridyl)ruthenium(II) complex linked via axial coordination of the distal pyridine moiety of the ruthenium complex to the zinc center. ${ }^{5 b}$ Fluorescence of the porphyrin donor was significantly quenched as a result of facile electron transfer to the ruthenium acceptor. 


\section{Experiment Design}

Herein we report the first examples of dynamic supramolecular assemblies composed of cyclometalated $\operatorname{Ir}(\mathrm{III})$ complexes of the form of $\left[\operatorname{Ir}\left(\mathrm{C}^{\wedge} \mathrm{N}\right)_{2}(\mathrm{qpy})\right] \mathrm{PF}_{6}$ (where $\mathrm{C}^{\wedge} \mathrm{N}$ is mesppy = 2-phenyl-4-mesitylpyridinato in $\mathbf{1 a}$ and $\mathbf{1} \mathbf{b}$ and dFmesppy $=2$-(4,6-difluorophenyl)-4mesitylpyridinato in $\mathbf{2 a}$ and $\mathbf{2} \mathbf{b}$, and qpy is $4,4^{\prime}: 2^{\prime}, 2^{\prime \prime}: 4^{\prime \prime}, 4^{\prime \prime \prime}$-quaterpyridine) that act as the donors, and zinc tetraphenylporphyrin (ZnTPP) that acts as the acceptor (Chart 1). In these systems, the ZnTPP can coordinate to one or both of the two distal pyridine rings of the $\left[\operatorname{Ir}\left(\mathrm{C}^{\wedge} \mathrm{N}\right)_{2}(\mathrm{qpy})\right] \mathrm{PF}_{6}$ complexes $\left(\left[\operatorname{Ir}(\text { mesppy })_{2} q p y\right] \mathrm{PF}_{6}, \quad \mathbf{1}\right.$ and $\left[\operatorname{Ir}(\mathrm{dFmesppy})_{2} q p y\right] \mathrm{PF}_{6}, \quad \mathbf{2}$, (Chart 1) forming the assemblies shown in Chart 2a. Complexes 1 and $\mathbf{2}$ were designed with the goal of modulating the donor energy as a function of the choice of $\mathrm{C}^{\wedge} \mathrm{N}$ ligand and to explore electronic communication between the two chromophoric units and ZnTPP in the assemblies 1a, 1b, 2a and $\mathbf{2 b}$ (Chart 2a).

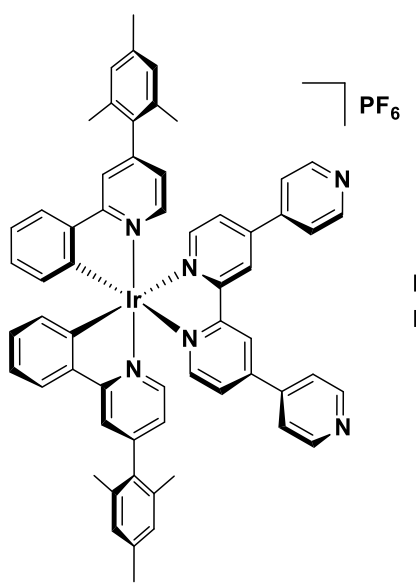

1

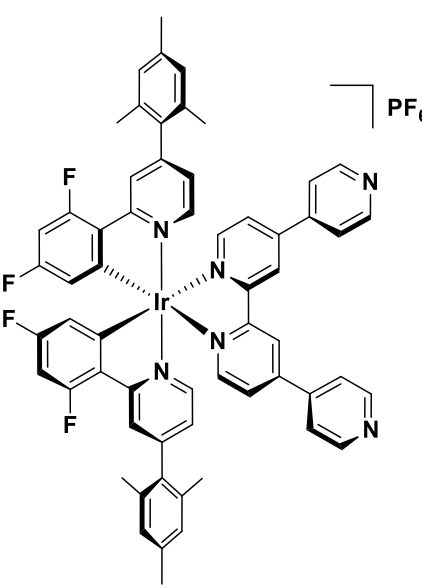

2

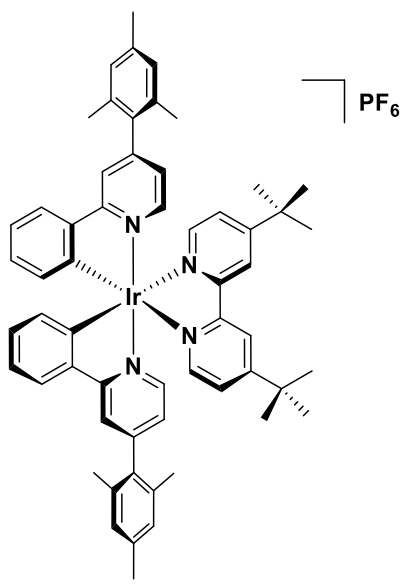

3

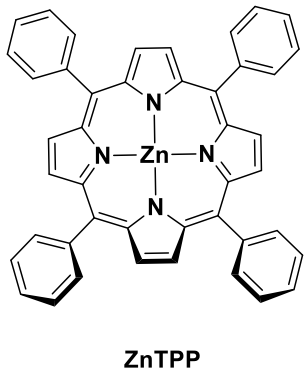

ZnTPP

Chart 1. Chemical structures of the reference mononuclear cyclometalated $\operatorname{Ir}(\mathrm{III})$ complexes

$\mathbf{1}, \mathbf{2}$ and $\mathbf{3}$ and ZnTPP under investigation in this work. 
The use of $\left[\operatorname{Ir}(\text { mesppy })_{2}(\right.$ dtbubpy $\left.)\right] \mathrm{PF}_{6}, 3$ (Chart 1) provides a useful negative control in the form of the "non-assembly" $\mathbf{3 a}$ (Chart $\mathbf{2 b}$ ) to verify the presence/absence of electronic communication between $\mathbf{1}$ or $\mathbf{2}$ and ZnTPP that is a direct result of axial coordination to $\mathrm{Zn}$ (dtbubpy is 4,4'-di-tert-butyl-2,2'-bipyridine). By combining one- and two-dimensional NMR spectroscopy $\left({ }^{1} \mathrm{H}\right.$ NMR titrations, 2D COSY and HETCOR NMR, and low-temperature ${ }^{1} \mathrm{H}$ NMR spectra), detailed optoelectronic investigations (UV-Vis and Near InfraRed (NIR) absorption spectroscopy, steady-state and time-resolved emission studies, including streak camera measurements, and cyclic voltammetry experiments) and X-ray single crystal structure analysis of the assemblies $\mathbf{1 a}, \mathbf{1 b}, \mathbf{2 a}$ and $\mathbf{2 b}$ (Chart $\mathbf{2 a}$ ), the nature of the interaction and electronic communication between Ir and $\mathrm{Zn}$ in these complexes is elucidated.

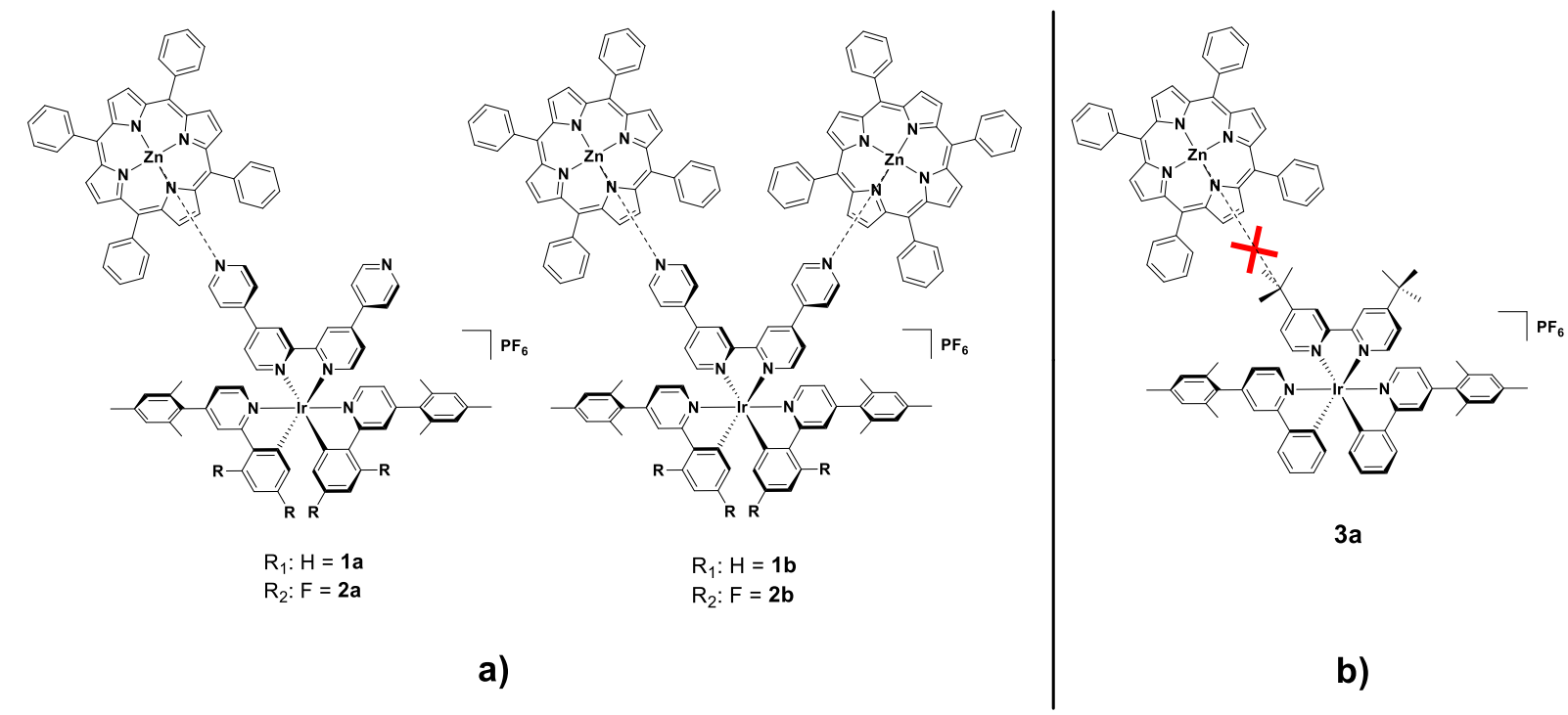

Chart 2. Chemical structures of a) the assemblies 1a $\left[\operatorname{Ir}(\text { mesppy })_{2}(q p y)\right] \mathrm{PF}_{6}: \mathrm{ZnTPP}_{1: 1}$ ratio and 2a $\left[\operatorname{Ir}(\mathrm{dFmesppy})_{2}(\mathrm{qpy}) \mathrm{PF}_{6}: \mathrm{ZnTPP}_{1: 1}\right.$ ratio; $\mathbf{1 b}\left[\operatorname{Ir}(\text { mesppy })_{2}(\mathrm{qpy})\right] \mathrm{PF}_{6}: \mathrm{ZnTPP}_{1: 2}$ ratio and 2b $\left[\operatorname{Ir}(\mathrm{dFmesppy})_{2}(\mathrm{qpy}) \mathrm{PF}_{6}: \mathrm{ZnTPP}_{1: 2}\right.$ ratio, and b) Chemical structure of complex 3 mixed with ZnTPP (3a) used as a control experiment.

\section{Results and Discussion}




\section{Synthesis.}

The syntheses of the $\mathrm{C}^{\wedge} \mathrm{N}$ and qpy ligands and the heteroleptic iridium complexes $\mathbf{1 - 3}$ are shown in Scheme 1. The mesppy and dFmesppy $\mathrm{C}^{\wedge} \mathrm{N}$ ligands were each prepared in high yield via Suzuki-Miyaura ${ }^{11}$ palladium-catalysed cross-coupling reactions. The bulky mesityl substituent was incorporated at the 4-position of the pyridine ring of ppy and $\mathrm{dFppy} \mathrm{C}^{\wedge} \mathrm{N}$ ligands as mesityl substitution had been previously shown by Bryce and co-workers ${ }^{12}$ for $\left[\operatorname{Ir}(\mathrm{dFmesppy})_{2}(\right.$ pic) $]$ (where pic is 2-piconilate) and Zysman-Colman and co-workers ${ }^{13}$ for $\left[\operatorname{Ir}(\mathrm{dFmesppy})_{2}(\mathrm{dppe}) \mathrm{PF}_{6}\right.$ (where dppe is 1,2-bis(diphenylphosphino)ethene)) to improve the solubility of the complex in organic solvents and to reduce intermolecular interaction. ${ }^{14}$



Scheme 1. Synthesis of $C^{\wedge} N$ and qpy ligands and $\left[\operatorname{Ir}\left(C^{\wedge} N\right)_{2}\left(N^{\wedge} N\right)\right] P F_{6}$ complexes $\mathbf{1}, 2$ and $\mathbf{3}$. Reagents and conditions: ${ }^{a} 2.0$ equiv. $\mathrm{K}_{2} \mathrm{CO}_{3}, 5 \mathrm{~mol} \% \mathrm{Pd}\left(\mathrm{PPh}_{3}\right)_{4}, \mathrm{~N}_{2}, 1,4$-dioxane $/ \mathrm{H}_{2} \mathrm{O}(4: 1$ $\mathrm{v} / \mathrm{v}), 105{ }^{\circ} \mathrm{C}, 56 \mathrm{~h} ;{ }^{b} 2.0$ equiv. $\mathrm{K}_{2} \mathrm{CO}_{3}, 5 \mathrm{~mol} \% \mathrm{Pd}\left(\mathrm{PPh}_{3}\right)_{4}, \mathrm{~N}_{2},\left(\mathrm{MeOCH}_{2}\right)_{2} / \mathrm{H}_{2} \mathrm{O}(4: 1 \mathrm{v} / \mathrm{v})$, $130{ }^{\circ} \mathrm{C}, 19 \mathrm{~h} ;{ }^{c} 2-\mathrm{EtOC}_{2} \mathrm{H}_{4} \mathrm{OH} / \mathrm{H}_{2} \mathrm{O}(4: 1 \mathrm{v} / \mathrm{v}), 110{ }^{\circ} \mathrm{C}, \mathrm{N}_{2}, 19 \mathrm{~h} .{ }^{d} \mathrm{DMF}, 10 \mathrm{~mol} \% \mathrm{Pd} / \mathrm{C}$, 
$165^{\circ} \mathrm{C}, 48 \mathrm{~h},{ }^{e}$ i. $\mathrm{CH}_{2} \mathrm{Cl}_{2} / \mathrm{MeOH}(2: 1 \mathrm{v} / \mathrm{v}), 55^{\circ} \mathrm{C}, 19 \mathrm{~h}, \mathrm{~N}_{2}$; ii. Excess solid $\mathrm{NH}_{4} \mathrm{PF}_{6} ;{ }^{f}$ $\mathrm{Zn}(\mathrm{OAc})_{2}, \mathrm{CHCl}_{3} / \mathrm{MeOH}(5: 1 \mathrm{v} / \mathrm{v}), 20^{\circ} \mathrm{C}, 10 \mathrm{~h}$.

The $\mathrm{C}^{\wedge} \mathrm{N}$ ligands were complexed with $\mathrm{IrCl}_{3} 3 \mathrm{H}_{2} \mathrm{O}$ and the resulting $\mu$-dichlorobridged iridium dimers $\left[\operatorname{Ir}(\text { mesppy })_{2} \mathrm{Cl}\right]_{2}, \mathbf{D 1}$ and $\left[\operatorname{Ir}(\mathrm{dFmesppy})_{2} \mathrm{Cl}\right]_{2}$, D2 were formed in good yield under standard conditions. ${ }^{15}$ The qpy ligand was prepared in low yield following an oxidative Pd-catalyzed coupling reaction of 4,4'-bipyridine. ${ }^{16}$ Complexes 1 and 2 were isolated through cleavage of D1 and D2 with qpy, whereas complex 3 was prepared through cleavage of D1 with dtbubpy. All complexes were purified by column chromatography and isolated as their hexafluorophosphate salt following an anion metathesis reaction using $\mathrm{NH}_{4} \mathrm{PF}_{6}$. Zinc tetraphenylphorphyrin (ZnTPP) was prepared in high yield by complexation of tetraphenylporphyrin with anhydrous zinc acetate. ${ }^{17}$ The purity of the complexes was confirmed by ${ }^{1} \mathrm{H},{ }^{13} \mathrm{C}$, and ${ }^{19} \mathrm{~F}$ NMR spectroscopy, HRMS and melting point analyses (see the Electronic Supplementary Information, ESI). HRMS analysis showed in each case the diagnostic molecular ion peak.

Assemblies 1a and 1b were rapidly obtained after mixing 1 with one or two equivalents of $\mathrm{ZnTPP}$, respectively, in $\mathrm{CD}_{2} \mathrm{Cl}_{2}$ at room temperature. The analogous assemblies $\mathbf{2 a}$ and $\mathbf{2 b}$ were formed upon mixing $\mathbf{2}$ with one or two equivalents of ZnTPP (Chart 2a). The formation of the assemblies was monitored by ${ }^{1} \mathrm{H}$ NMR, 2D COSY, HMBC and HMQC and ${ }^{19}$ F NMR experiments and HRMS spectrometry (NMR data are reported in the ESI). Crystal structures of $\mathbf{1}, \mathbf{3}, \mathbf{1 a}$ and $\mathbf{1 b}$ were obtained through X-ray single-crystal diffraction (vide infra), which confirmed the identity of the assemblies under study. 


\section{Solution-state structural elucidation.}

The assignment of all of the resonances in the ${ }^{1} \mathrm{H}$ NMR spectrum of $\mathbf{1}, \mathbf{1 a}$ and $\mathbf{1 b}$ (Figure S41) was carried out using 2D ${ }^{1} \mathrm{H}-{ }^{1} \mathrm{H}$ COSY, ${ }^{1} \mathrm{H}_{-}{ }^{13} \mathrm{C} \mathrm{HMBC}$ and ${ }^{1} \mathrm{H}-{ }^{13} \mathrm{C}$ HMQC NMR experiments. After mixing 1 with one equivalent of $\mathrm{ZnTPP}$ in $\mathrm{CD}_{2} \mathrm{Cl}_{2}$ (1a, Figure $\mathbf{4 h}$ ), the proton resonances associated with 1 experienced an upfield shift (Figure 4c). As expected, the proton resonances associated with the qpy moiety $\left(\mathrm{H}^{\mathrm{a}}, \mathrm{H}^{\mathrm{b}}, \mathrm{H}^{\mathrm{c}}, \mathrm{H}^{\mathrm{d}}\right.$ and $\mathrm{H}^{\mathrm{e}}$ in Figure 4h) were most sensitive to the axial coordination of the pyridine ring to ZnTPP. After the addition of a second equivalent of ZnTPP, the qpy proton resonances experienced a further upfield (Figure 4d). The formation of $\mathbf{1 a}$ and $\mathbf{1 b}$ takes place essentially instantaneously after mixing 1 with ZnTPP and, after their formation, no further changes in the ${ }^{1} \mathrm{H}$ NMR spectra were observed. This observation has been described ${ }^{5 b, 10 b, 18}$ for many axial interactions between $\mathrm{N}$-donor ligands and ZnTPP.

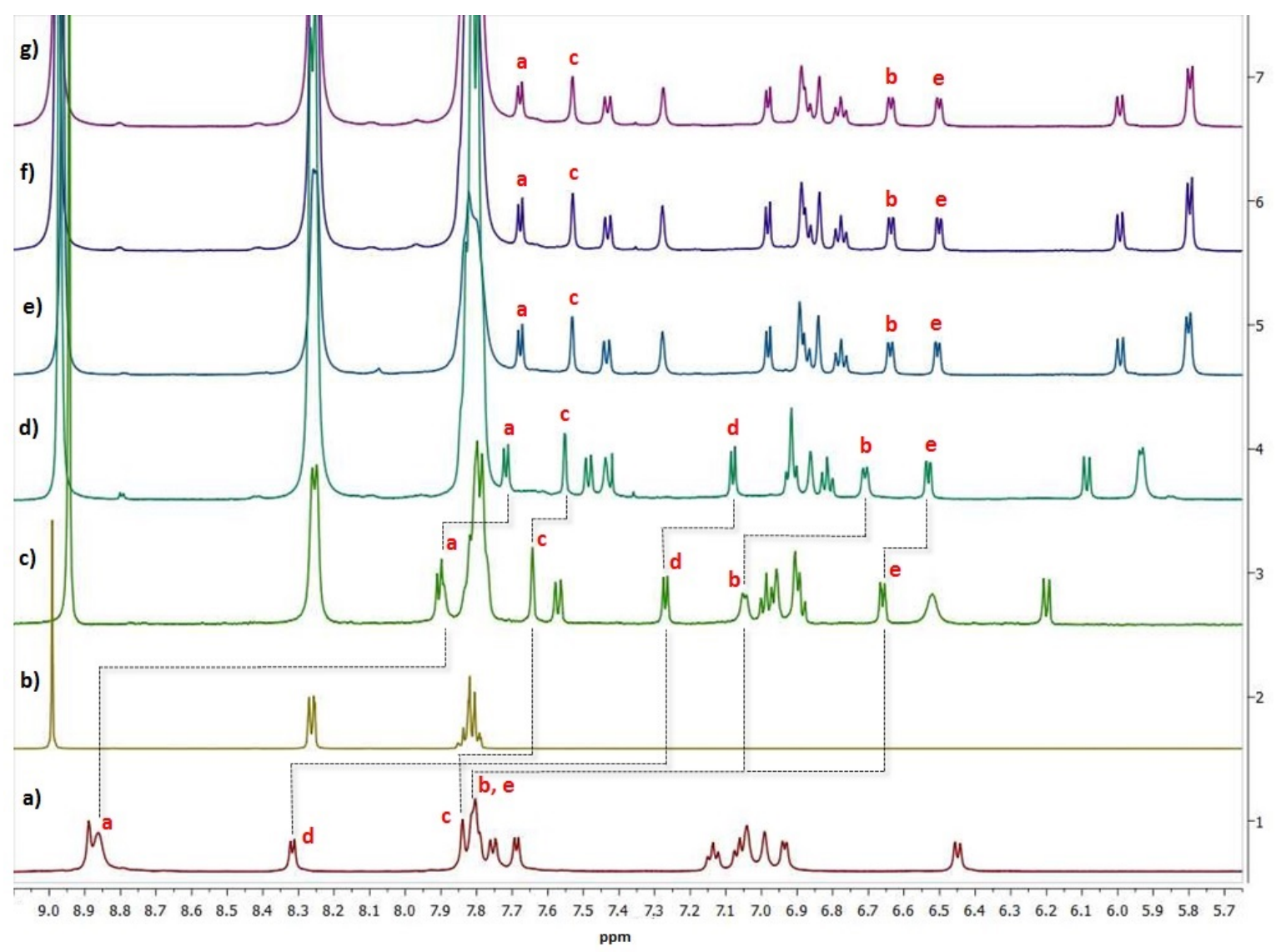




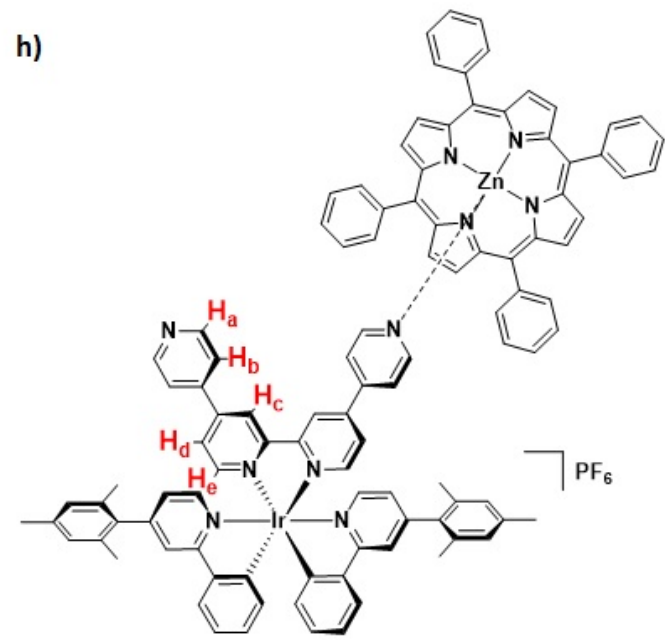

$1 \mathbf{a}$

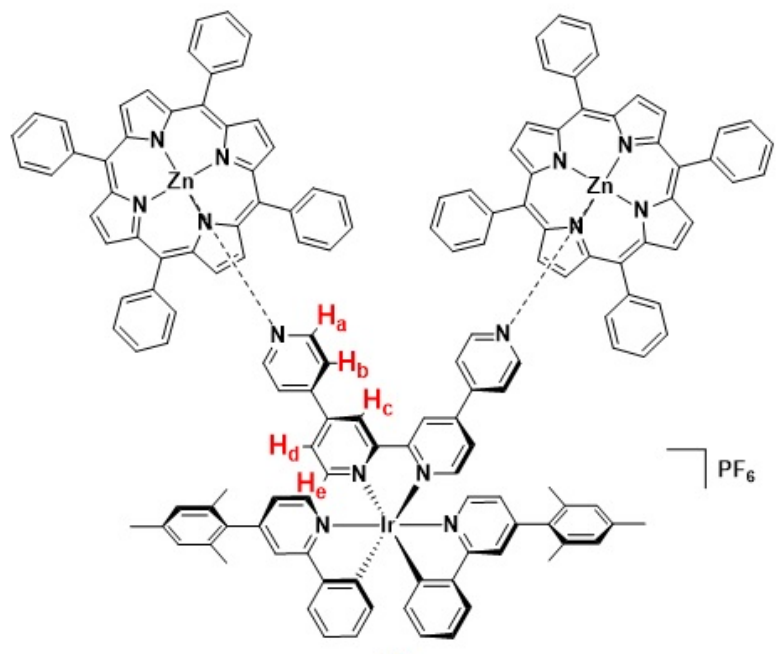

1b

Figure 4. ${ }^{1} \mathrm{H}$ NMR spectra $\left(\mathrm{CD}_{2} \mathrm{Cl}_{2}, 500 \mathrm{MHz}\right)$ of. a) 1 (298 K); b) ZnTPP $(298 \mathrm{~K})$; c) 1a $(298 \mathrm{~K})$; d) $\mathbf{1 b}(298 \mathrm{~K})$; e) 1a $(236 \mathrm{~K})$; f) $\mathbf{1 b}(236 \mathrm{~K})$; g) 1 mixed with 4 equivalents of ZnTPP $(236 \mathrm{~K})$. The spectral assignments correspond to the labeling scheme in $\mathbf{h}$.

The ${ }^{1} \mathrm{H}$ NMR spectrum for 1a (Figure 4c) is relatively simple, indicating a local $C_{2}$ symmetry around the iridium center. This observation suggests that the exchange of bound and unbound ZnTPP is fast compared to the NMR chemical shift timescale and that the ${ }^{1} \mathrm{H}$ NMR spectrum observed reflects a mixed speciation of ZnTPP - both free ZnTPP and ZnTPP bound to 1. Titration of ZnTTP into a $3.09 \mathrm{mM}$ solution of 1 in $\mathrm{CD}_{2} \mathrm{Cl}_{2}$ results in the expected upfield shift of the resonance arising from $\mathrm{H}^{\mathrm{a}}$ from $\delta 8.90$ to $\delta 7.55$ as the concentration of ZnTPP is increased from 0 to $8.95 \mathrm{mM}$. This ${ }^{1} \mathrm{H}$ NMR titration data could be fitted to a sequential binding model (Figure 5) and affords an equilibrium constant of $8000 \pm$ $370 \mathrm{M}^{-1}$ for the formation of $\mathbf{1 a}$ from $\mathbf{1}$ and ZnTPP and $2000 \pm 190 \mathrm{M}^{-1}$ for the formation of 1b from 1a and ZnTPP. These data can then be used to construct speciation plots for complexes $\mathbf{1 a}$ and $\mathbf{1 b}$ as a function of the initial concentration and the stoichiometry of the mixture. For solutions containing 1:1 mixture of $\mathbf{1}$ and ZnTPP initially, 1a is the dominant 
complex at all concentrations between $100 \mu \mathrm{M}$ and $100 \mathrm{mM}$. For solutions containing 1:2 mixture of $\mathbf{1}$ and ZnTPP initially, 1a is the dominant complex at concentrations below 600 $\mu \mathrm{M}$ and $\mathbf{1 b}$ is the dominant complex between this concentration and $100 \mathrm{mM}$.
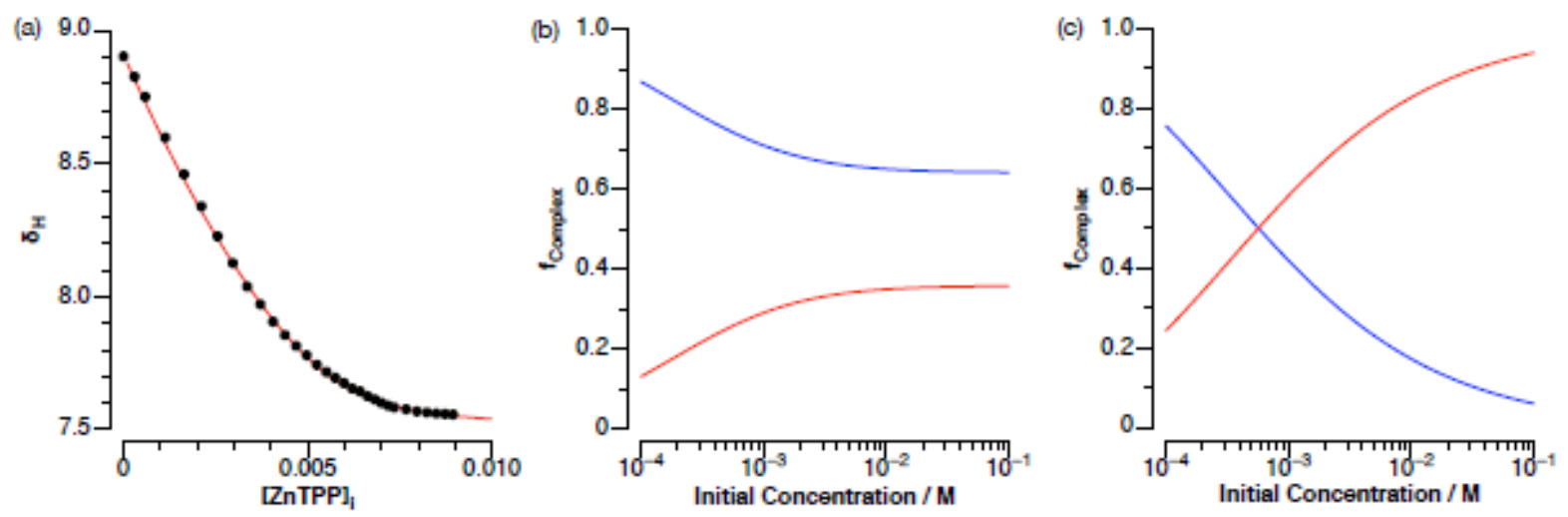

Figure 5. (a) The chemical shift changes observed in the ${ }^{1} \mathrm{H}$ NMR spectrum of a $3.09 \mathrm{mM}$ solution of 1 in $\mathrm{CD}_{2} \mathrm{Cl}_{2}$ upon addition of aliquots of $\mathrm{ZnTPP}$ (black points) are fitted (red line) to a sequential binding model corresponding to the formation of $\mathbf{1 a}$ and $\mathbf{1 b}$. Fractions of $1: 1$ complex 1a (blue lines) and 1:2 complex 1b (red lines) present in solution as a function of concentration when (b) $[\mathrm{ZnTPP}]_{\text {initial }}=[\mathbf{1}]_{\text {initial }}$ and (c) $[\mathrm{ZnTPP}]_{\text {initial }}=2 \times[\mathbf{1}]_{\text {initial }}$.

The lower association constant for the binding of the second ZnTPP molecule to form 1b was expected, as the coordination of a second ZnTPP to 1a would be somewhat impeded as a result of the steric bulk of the already-bound ZnTPP. The association constants for the formation of $\mathbf{1 a}$ and $\mathbf{1 b}$ are in the range reported for coordination between zinc porphyrins and monotopic nitrogen ligands such as pyridine, with measured association constants ranging between $K_{\mathrm{a}}=10^{2}$ and $10^{5} \mathrm{M}^{-1} .^{5 \mathrm{~b}, 10 \mathrm{~b}}$ The addition of more than 2 equivalents of ZnTPP to 1 results in no further changes in the ${ }^{1} \mathrm{H}$ NMR spectra (Figure $\mathbf{S 4 2}$ ).

The low-temperature (236 K) ${ }^{1} \mathrm{H}$ NMR spectra of 1a (Figure 4e), 1b (Figure 4f) and of $\mathbf{1}$ in the presence of 4 equivalents of ZnTPP (Figure $\mathbf{4 g}$ ) are all similar. These results 
suggest that at $236 \mathrm{~K}$ similar speciation exists, regardless of relative stoichiometry of $\mathbf{1}$ and ZnTPP, due to the slowing of the interchange processes between ZnTPP and the two distal pyridine moieties of the qpy ligand.

${ }^{1} \mathrm{H}$ NMR DOSY experiments of $\mathbf{1}, \mathbf{1 a}$ and $\mathbf{1 b}$ in $\mathrm{CD}_{2} \mathrm{Cl}_{2}$ at room temperature were carried out in order to estimate the diffusion coefficients of the three entities in solution and the results are reported in Figures S13, S29 and S36, respectively. Although 1a and 1b possess higher molecular weights than $\mathbf{1}$, similar diffusion coefficients of $c a$. D $=1.35 \times 10^{-9}$ $\mathrm{m}^{2} \cdot \mathrm{s}^{-1}$ have been obtained for the three entities. These results corroborate the dynamic and weak $\mathrm{N}-\mathrm{Zn}$ coordination for $\mathbf{1 a}$ and $\mathbf{1 b}$. As expected, when $\mathbf{3}$ was mixed with 2 equivalents of ZnTPP no change was observed in the ${ }^{1} \mathrm{H}$ NMR spectra (Figure $\mathbf{S 4 5}$ ), which clearly confirms that the upfield shifting of the protons in $\mathbf{1 a}$ and $\mathbf{1 b}$ compared to $\mathbf{1}(c f$. Figure $\mathbf{4}$ ) results from $\mathrm{N}_{\text {pyr }}$ ZZn coordination.

\section{Crystal Structures.}

Crystal structures of $\mathbf{1}, \mathbf{1 a}$ and $\mathbf{1 b}$ (Figure 6) were obtained through single-crystal Xray diffraction studies. The crystal structures of $\mathbf{3}$ and ZnTPP coordinated to diethyl ether were also obtained and are presented in the ESI (Figure S46), along with crystallographic data for all complexes. Diffraction for complexes 1a and 1b was very weak, but despite this, the structures of the two complexes could be unambiguously determined. In $\mathbf{1}, \mathbf{1 a}$ and $\mathbf{1 b}$ the iridium center adopts a distorted octahedral geometry, with the two nitrogen atoms of the $\mathrm{C}^{\wedge} \mathrm{N}$ ligands are mutually trans while the two nitrogen atoms of the qpy ligand are disposed trans with respect to the two $\operatorname{Ir}-\mathrm{C}_{\mathrm{C}^{\wedge} \mathrm{N}}$ bonds, as observed for other $\left[\operatorname{Ir}\left(\mathrm{C}^{\wedge} \mathrm{N}\right)_{2}\left(\mathrm{~N}^{\wedge} \mathrm{N}\right)\right] \mathrm{PF}_{6}$ complexes in the literature. ${ }^{19}$ Notably, the geometries (bond lengths and angles) of $\mathbf{1}$ do not 
differ markedly from those of $\mathbf{1 a}$ and $\mathbf{1 b}$, indicating little perturbation of the local structure of iridium upon coordination of 1 with $\mathrm{ZnTPP}$. For all three structures the $\operatorname{Ir}-\mathrm{N}_{\mathrm{C}^{\wedge} \mathrm{N}}$ bonds are $c a$. $2.03 \AA$, the Ir- $\mathrm{C}_{\mathrm{C}^{\wedge} \mathrm{N}}$ bonds $c a .2 .00 \AA$, and the Ir- $\mathrm{N}_{\mathrm{N}^{\wedge} \mathrm{N}}$ bonds $c a .2 .12 \AA$, which are close to the values reported for other $\left[\operatorname{Ir}\left(\mathrm{C}^{\wedge} \mathrm{N}\right)_{2}\left(\mathrm{~N}^{\wedge} \mathrm{N}\right)\right] \mathrm{PF}_{6}$ complexes. ${ }^{19-20}$ In each complex, an orthogonal orientation of the mesityl ring with respect to the pyridine ring is observed (torsion angles $c a$. $\left.90.5^{\circ}\right)$. This feature was also observed in the crystal structures reported for other mesitylcontaining iridium complexes. ${ }^{13}$ The four pyridine rings of the qpy moiety in each of $\mathbf{1}, \mathbf{1 a}$ and $\mathbf{1 b}$ are not completely coplanar but instead adopt a torsion angle of approximately $-40^{\circ}$ between each of the two distal pyridine rings and the central bipyridyl moiety. 
a)

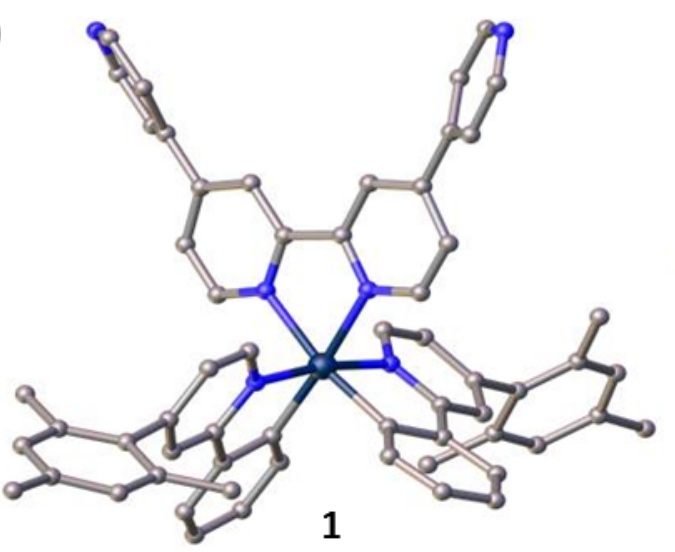

1

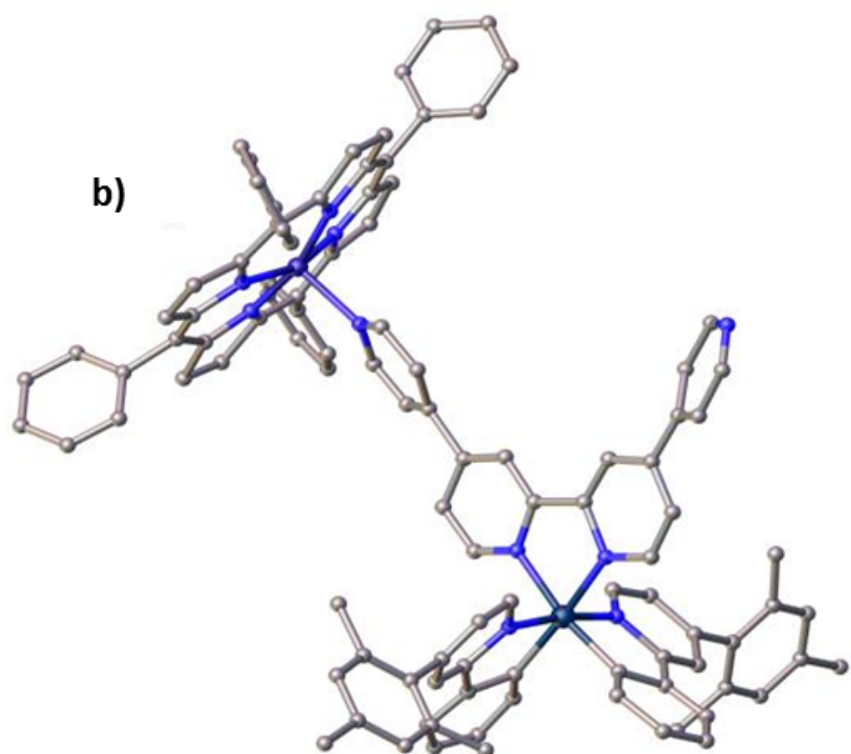

$1 a$

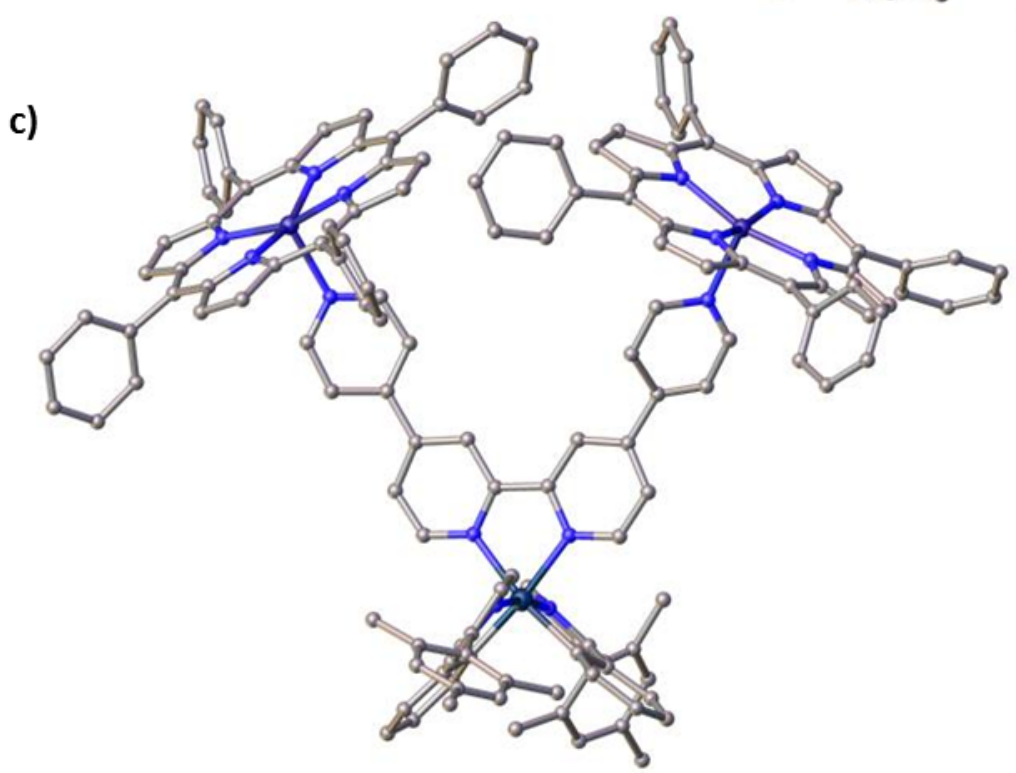

1b

Figure 6. Views of the structures of (a) 1; (b) $\mathbf{1 a}$; and (c) $\mathbf{1 b}$, with $\mathrm{PF}_{6}^{-}$anions, solvent molecules, minor disorder components and hydrogen atoms omitted for clarity.

In all the structures, the bond angles between the iridium center and the qpy ligand $\left(\mathrm{N}_{\mathrm{qpy}}-\mathrm{Ir}-\mathrm{N}_{\mathrm{qpy}}\right)$ are essentially the same, ranging between $76.29(19)$ and $79.2(7)^{\circ}$. In $\mathbf{1 a}$ and $\mathbf{1 b}$, the $\mathrm{Zn}-\mathrm{N}_{\text {pyridyl }}$ bond distances are approximately $2.15 \AA$, which are in agreement with the typical bond length values between $\mathrm{N}$-donor ligands and $\mathrm{ZnTPP}^{21}$ In $\mathbf{1 a}$ and $\mathbf{1 b}$ the qpy 
moieties show vector angles of, respectively, 74.16 and $64.68^{\circ}$ (Figure S46) appropriate to accommodate either one or two ZnTPP molecules around one iridium complex (Chart 2a) resulting in Ir “ Zn separations of 11.22-11.33 $\AA$. Solid-state NMR of bulk samples of 1 and 1a are consistent with the solid-state structures (see the solid-state NMR section in the ESI).

\section{Photophysical properties.}

\section{Absorption.}

The optoelectronic properties of all compounds were investigated in DCM solutions at varying concentrations between $5 \times 10^{-4}$ (above $\mathrm{k}_{\mathrm{d}}$ ) and $1 \times 10^{-6}$ (below $\mathrm{k}_{\mathrm{d}}$ ) M at room temperature and the results are summarized in Tables $\mathbf{S 2}$ and S3. In addition, DFT and TDDFT calculations (see computational details in the ESI) were performed to gain insights into the nature of the electronic transitions of the different complexes and assemblies. At a concentration of $1 \times 10^{-6} \mathrm{M}$, less than $1 \%$ of ZnTPP is actually bound to the qpy ligand in 1a, $\mathbf{1 b}, \mathbf{2 a}$ and $2 \mathbf{b}$ whereas at a concentration of $5 \times 10^{-4} \mathrm{M} c a .90 \%$ of the ZnTPP is bound to the iridium complex. After mixing $\mathbf{1}$ and ZnTPP in a 1:1 ratio, a speciation of $\mathbf{1}: \mathbf{1 a}: \mathbf{1 b}=0.3: 1.3: 1$ exists. After mixing 1 with two equivalents of ZnTPP, leads to a speciation of 1:1a:1b = $0.2: 1: 1.4 .^{22}$

The UV-Visible (UV-Vis) and Near Infra-Red (NIR) absorption spectra of ZnTPP, 1b, 2b, 3a and ZnTPP coordinated to pyridine (ZnTPP-py, used as a reference assembly) are shown in Figure 7a (the UV-Vis absorption spectra of complexes 1-3 are shown in Figure S49). The absorption spectra of all the iridium complexes are characterized by two intense bands between $260 \mathrm{~nm}$ and $330 \mathrm{~nm}$ and a broad, lower-intensity band at around $390 \mathrm{~nm}$. These bands are well reproduced by the TD-DFT calculations using the B3LYP exchange- 
correlation functional (see, for example, the UV-Vis spectra of $\mathbf{1}$ and $\mathbf{2}$ in Figures S77a and S80, respectively). A comparison with the TD-CAM-B3LYP results is provided in Figure S77b for 1. This range-separated functional generally yields blue-shifted bands compared to experiment, therefore we have used the former functional for the rest of complexes. ${ }^{23}$ In line with other cationic iridium complexes of the form $\left[\operatorname{Ir}\left(\mathrm{C}^{\wedge} \mathrm{N}\right)_{2}\left(\mathrm{~N}^{\wedge} \mathrm{N}\right)\right]^{+},{ }^{56-59,86}$ the two higher energy bands are theoretically assigned to spin-allowed ${ }^{1} \pi \rightarrow \pi^{*}$ ligand centered ( $\left.{ }^{1} \mathrm{LC}\right)$ transitions localized on the $C^{\wedge} \mathrm{N}$ ligands, while the broad bands at wavelengths $>350 \mathrm{~nm}$ are due to several metal-to-ligand charge transfer and ligand-to-ligand charge transfer transitions $\left({ }^{1} \mathrm{MLCT} /{ }^{1} \mathrm{LLCT}\right) .{ }^{19,24}$ This absorption band in $\mathbf{2}$ is blue-shifted $\left(\lambda_{\max } c a .360 \mathrm{~nm}\right)$ compared to 1 due to presence of the electron-withdrawing fluorine atoms on the $\mathrm{C}^{\wedge} \mathrm{N}$ ligands, which stabilize the highest occupied molecular orbital (HOMO) and consequently increase the band gap..$^{25}$ The energy levels of the frontier orbitals of $\mathbf{1}$ and $\mathbf{2}$ are given in Figure S78.

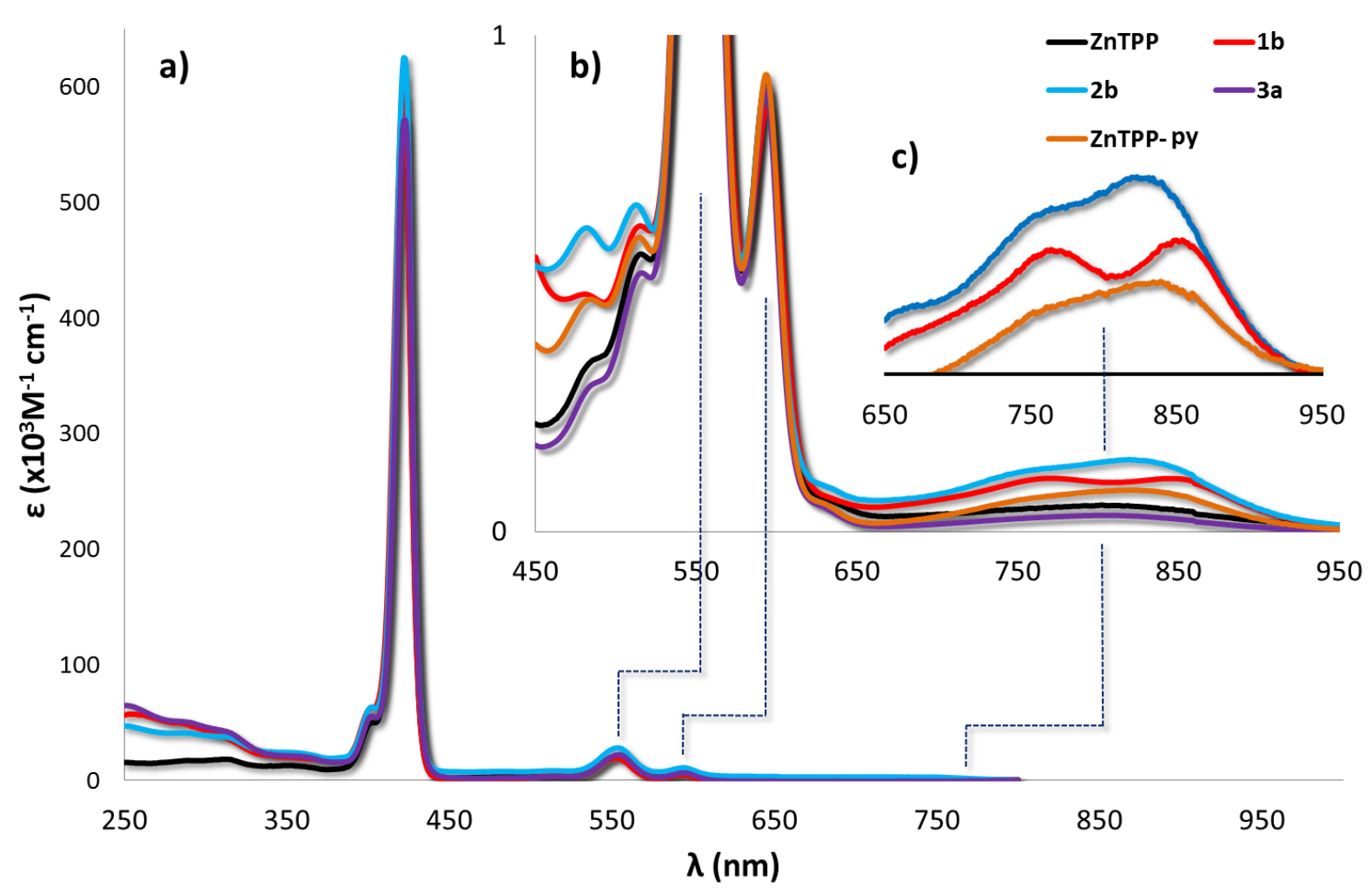


Figure 7. a) UV-Vis absorption spectra of ZnTPP, 1b, 2b and 3a recorded in DCM at $298 \mathrm{~K}$ at a concentration of approximately $10^{-6}$ M. b) NIR-absorption spectra from 450 to $950 \mathrm{~nm}$ of ZnTPP, 1b, 2b, 3a and ZnTPP-pyridine recorded in DCM at $298 \mathrm{~K}$ at a concentration of $5 \times$ $10^{-4}$ M. c) expansion of the NIR-absorption spectra from 650 to $950 \mathrm{~nm}$ of ZnTPP, 1b, 2b and ZnTPP-pyridine after mathematical subtraction of the absorption of free ZnTPP.

The UV-Vis absorption spectrum of ZnTPP (Figure 7a) is characterized by two major bands. The intense absorption between 400 and $430 \mathrm{~nm}$ (Soret band) is due to a ${ }^{1} \pi \rightarrow \pi^{*}$ transition $\left(\mathrm{S}_{2}\right)$ localized on the porphyrin moiety while the low-intensity absorption band between 500 and $600 \mathrm{~nm}$ shows vibronic structures and originates from the ${ }^{1} \pi \rightarrow \pi^{*}$ electronic excitation $\left(\mathrm{S}_{1}\right)$, the so-called Q-bands. ${ }^{8}{ }^{17}$ As shown in Figure $\mathbf{S 7 9}$, good agreement with the computed TD-DFT results is obtained. The absorption spectra of $\mathbf{1 b}, \mathbf{2 b}$, and $\mathbf{3 a}$ collected at a concentration of approximately $10^{-6} \mathrm{M}$ (association $<1 \%$ ) are very similar in profile to that of ZnTPP and show the sum of the absorptivities of the iridium complexes and ZnTPP, without any significant interactions between the two (Figure 7a).

NIR absorption spectroscopy of ZnTPP, 1b, 2b, 3a and ZnTPP-py collected in DCM at a concentration of $5 \times 10^{-4} \mathrm{M}$ are shown in Figure $7 \mathbf{b}$. For metallo-porphyrins, the presence of broad and weak absorption bands between 820 and $850 \mathrm{~nm}$ are generally ascribed to the formation of molecular aggregates, which can occur at a concentration higher than $10^{-5}$ M. ${ }^{26}$ Indeed, in each of ZnTPP, ZnTPP-py, 2a, 2b and 3a, there is a weak and broad absorption band centered at approximately $800 \mathrm{~nm}$. However, compared to ZnTPP, which shows a single broad and unstructured absorption band in the NIR, there are two distinct bands observed with enhanced absorptivity at 768 and $853 \mathrm{~nm}$ for $\mathbf{1 b}$ and 755 and $827 \mathrm{~nm}$ for 
$\mathbf{2 b}$, respectively. This behavior matches the profile of ZnTPP-py, which was formed in situ upon addition of an excess pyridine to ZnTPP (Figure 7b). By contrast, for 3a, where no coordination between the chromophoric units takes place, the NIR absorption profile is very similar to that of ZnTPP. Importantly, for metallo-porphyrins spin-forbidden singlet-triplet transitions are possible and, as previously reported, the axial coordination between $\mathrm{N}$-donor ligands and ZnTPP can easily perturb the lowest triplet excited states of ZnTPP. ${ }^{27}$ From our experiments, the enhanced absorptivity in the NIR observed for $\mathbf{1 b}$ and $\mathbf{2 b}$ seems to be primarily due to perturbation the triplet state of $\mathrm{ZnTPP}$, which is promoted by the axial coordination between the distal pyridines of $\mathbf{1}$ and $\mathbf{2}$ with ZnTPP; though porphyrin aggregation cannot be ruled out as contributing to this absorption band. In view of the TDDFT results, the NIR absorption observed for $\mathbf{1 b}$ and $\mathbf{2} \mathbf{b}$ can tentatively be assigned to $\mathrm{T}_{1}$ and $\mathrm{T}_{2}$ (both located at $750 \mathrm{~nm}$ ). Note that, within the computational approach employed, the triplet excitation energies have no intensity because spin-orbit coupling (SOC) was neglected.

Notably, the absorption spectra shown in Figure $\mathbf{7 b}$ are the weighted superposition of the assemblies and free mononuclear complexes ZnTPP, $\mathbf{1}$ and $\mathbf{2}$. Figure 7c shows the deconvoluted absorption spectra for $\mathbf{1 b}, \mathbf{2 b}$ and ZnTPP-py after mathematical subtraction of the absorption spectrum of unbound ZnTPP. The remarkable enhancement of the NIR absorption in $\mathbf{2 a}$ and $\mathbf{2 b}$ showcases the sensitivity of the triplet excited-state of ZnTPP to the presence and nature of the axially bound ligand. As a result, upon coordination to the ZnTPP, new CT singlet and triplet excited-states arise in the assemblies. A very low intensity $\pi_{\text {por }} \rightarrow \pi_{\text {dtbbpy }} *$ CT transition $\left(\mathrm{S}_{1}\right)$, which is predicted by TD-DFT to occur at $736 \mathrm{~nm}$ (using the CAM-B3LYP functional for this obviously long-range CT transition), might importantly contribute (along with the ZnTPP-based lowest triplet excited states) to the low-energy UV- 
Vis bands. These new bands significantly contribute to the observed enhancement of the NIR features of the assemblies.

\section{Electrochemical properties.}

The ground-state electronic communication between the iridium and ZnTPP moieties in $\mathbf{1 a}, \mathbf{1 b}, \mathbf{2 a}$ and $\mathbf{2 b}$ has been investigated by cyclic voltammetry, the data of which is reported in Table $\mathbf{S} \mathbf{4}$ and the cyclic voltammograms (CVs) of $\mathbf{1}, \mathrm{ZnTPP}, \mathbf{1 a}$ and $\mathbf{1 b}$ are shown in Figure 8a (the CVs of $\mathbf{3}$ and $\mathbf{3 a}$ are reported in Figure $\mathbf{8 b}$ while the CVs of $\mathbf{2} \mathbf{a}$ and $\mathbf{2 b}$ and are reported in the Figure S72). The CVs were recorded in deaerated DCM solution containing $n-\mathrm{NBu}_{4} \mathrm{PF}_{6}$ as the supporting electrolyte and using $\mathrm{Fc} / \mathrm{Fc}^{+}$as an internal standard at $298 \mathrm{~K}$ at a concentration of the iridium complexes of $1.46 \times 10^{-3} \mathrm{M}$. At this concentration, for 1a, 2a, $\mathbf{1 b}$ and $\mathbf{2 b}, \mathrm{ZnTPP}$ is completely bound to iridium. After mixing $\mathbf{1}$ and ZnTPP in a 1:1 ratio, a speciation of $\mathbf{1 : 1 a : 1 b}=0.1: 5: 1$ exists; after mixing $\mathbf{1}$ with two equivalents of ZnTPP, a speciation of $\mathbf{1 : 1 a : 1 b}=0.1: 1: 6$ is formed $^{22}$ In agreement with the previously reported electrochemistry, ${ }^{28} \mathrm{ZnTPP}$ exhibits two mono-electronic irreversible reduction processes that are ascribed to the formation of the porphyrin radical anion [porph] ${ }^{-}$and dianion species $[\mathrm{porph}]^{2-}$ at $\mathrm{E}^{\mathrm{pc}}=-1.29 \mathrm{~V}$ and $-1.52 \mathrm{~V}$, respectively. There are two mono-electronic reversible oxidation processes due to the formation of the porphyrin radical cation [porph $]^{+}$ and dication species, $[\text { porph }]^{2+}$ at $\mathrm{E}^{\mathrm{ox}}{ }_{1 / 2}=0.75 \mathrm{~V}$ and $1.05 \mathrm{~V}$, respectively (ZnTPP in Figure 8). Similar to the CVs of other cationic heteroleptic $\operatorname{Ir}(\mathrm{III})$ complexes, ${ }^{24 \mathrm{a}} \mathbf{1}$ exhibits one quasireversible reduction wave at $\mathrm{E}_{1 / 2}^{\mathrm{red}}=-1.21 \mathrm{~V}$ attributed to the first reduction of the qpy ligand (note that the LUMO is located on this ligand, as shown in Figure S78) and one irreversible oxidation at $\mathrm{E}^{\mathrm{pa}}=1.35 \mathrm{~V}$ assigned to the $\mathrm{Ir}^{\mathrm{III}} / \mathrm{Ir}^{\mathrm{IV}}$ redox couple with significant contribution from the $\mathrm{C}^{\wedge} \mathrm{N}$ ligands (1 in Figure 8a, see also the HOMO in Figure $\mathbf{S 7 8}$ ). 
For the assemblies 1a and 1b, the oxidation potentials localized on the iridium complex are only slightly cathodically shifted compared to $\mathbf{1}\left(\mathrm{E}^{\mathrm{pa}}=1.35 \mathrm{~V}\right.$ for $\mathbf{1} v s . \mathrm{E}^{\mathrm{pa}}=1.34$ $\mathrm{V}$ for $\mathbf{1 a}$ and $\mathrm{E}^{\mathrm{pa}}=1.33 \mathrm{~V}$ for $\left.\mathbf{1 b}\right)$. However, remarkable changes are observed for the redox processes localized on ZnTPP. Indeed, compared to ZnTPP, the Zn-centered oxidation waves of both 1a and $\mathbf{1 b}$ exhibit a cathodic shift $\left(\mathrm{E}^{\mathrm{ox}}{ }_{1 / 2}=0.40 \mathrm{~V}\right.$ for $\mathbf{1 a}, \mathrm{E}^{\mathrm{ox}}{ }_{1 / 2}=0.36 \mathrm{~V}$ for $\mathbf{1 b} v s$. $\mathrm{E}^{\mathrm{ox}}{ }_{1 / 2}=0.75 \mathrm{~V}$ for ZnTPP) and their first reduction processes are likewise cathodically shifted $\left(\mathrm{E}_{1 / 2}^{\mathrm{red}}=-1.39 \mathrm{~V}\right.$ for 1a, $\mathrm{E}_{1 / 2}^{\mathrm{red}}=-1.40 \mathrm{~V}$ for $\mathbf{1 b} v s . \mathrm{E}^{\mathrm{pc}}=-1.29 \mathrm{~V}$ for ZnTPP $)$. This behavior mirrors the electrochemistry of ZnTPP coordinated with N-donor electron-donating ligands, ${ }^{18 b,}{ }^{28-29}$ making the ZnTPP more easily oxidized and less easily reduced. The CV of ZnTPP coordinated with pyridine (ZnTPP-py) (Figure S74) corroborates the observed trends in the CVs for $\mathbf{1 a}$ and $\mathbf{1 b}$, where both the reduction and the oxidation waves of ZnTPP-py are shifted cathodically $\left(\mathrm{E}^{\mathrm{ox}}{ }_{1 / 2}=0.69 \mathrm{~V}, \mathrm{E}^{\mathrm{ox}}{ }_{1 / 2}=0.36 \mathrm{~V}, \mathrm{E}^{\mathrm{red}}{ }_{1 / 2}=-1.61 \mathrm{~V}\right)$ relative to ZnTPP. 

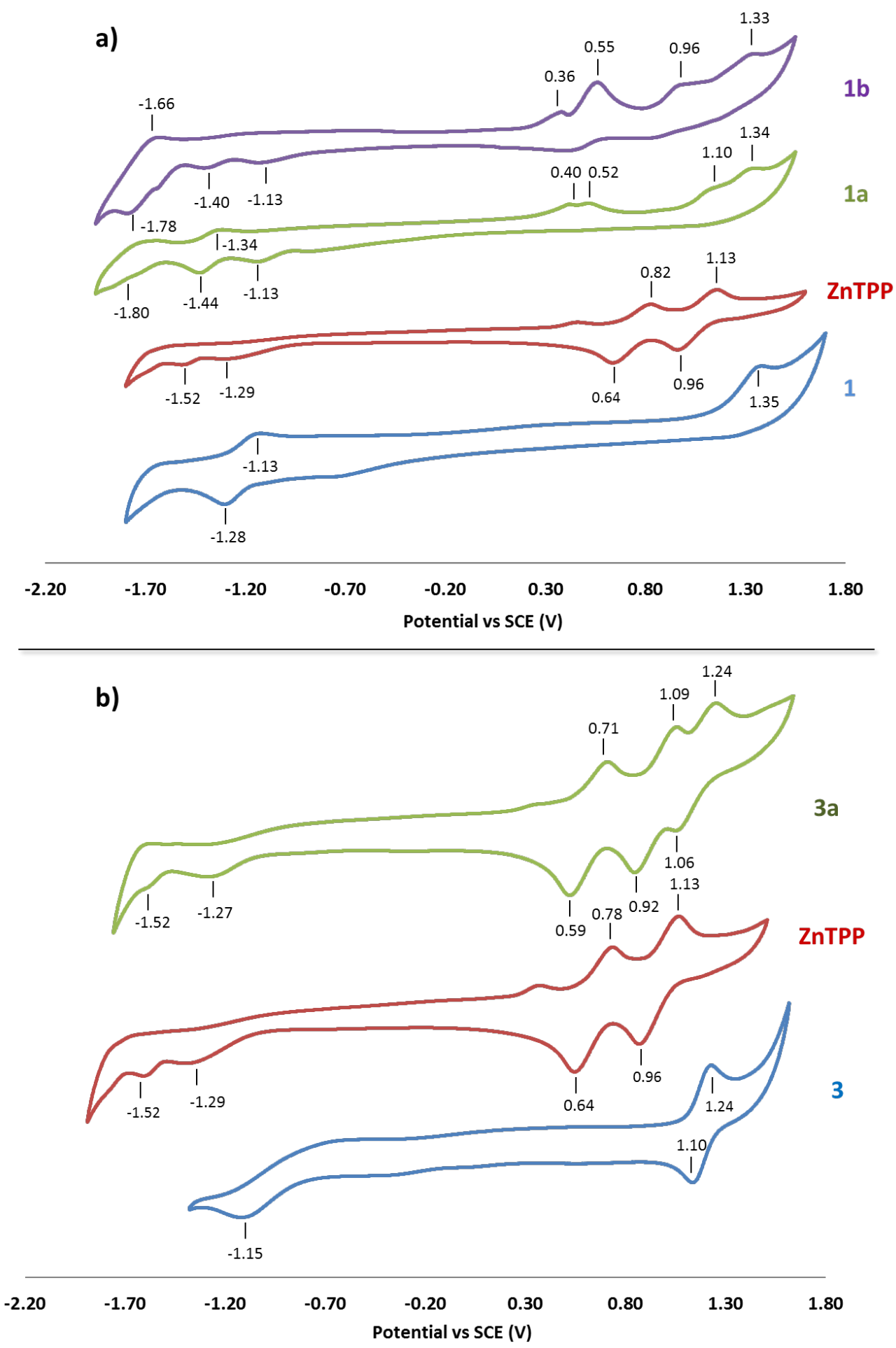

Figure 8. a) CVs for 1, ZnTPP, 1a and $\mathbf{1 b}$ and b) CVs for 3, ZnTPP and 3a recorded at $298 \mathrm{~K}$ in deaerated DCM solution containing $n-\mathrm{NBu}_{4} \mathrm{PF}_{6}$ as the supporting electrolyte and using $\mathrm{Fc} / \mathrm{Fc}^{+}$as an internal standard $\left(\mathrm{Fc} / \mathrm{Fc}^{+}=0.46 \mathrm{~V}\right.$ in $\mathrm{DCM}$ with respect to $\left.\mathrm{SCE}\right) .^{30}$ 
The electrochemistry of $\mathbf{2}, \mathbf{2 a}$ and $\mathbf{2 b}$ was also investigated (Figure $\mathbf{S 7 3}$ ) and the trends match those presented above. CVs of $\mathbf{3}$ and $\mathbf{3 a}$ are shown in Figure $\mathbf{8 b}$. In deaerated $\mathrm{DCM}, 3$ exhibits one irreversible reduction at $\mathrm{E}^{\mathrm{red}}=-1.15 \mathrm{~V}$ attributed to the reduction of the dtbubpy ligand and one reversible oxidation at $\mathrm{E}^{\mathrm{ox}}{ }_{1 / 2}=1.17 \mathrm{~V}$, assigned to the $\mathrm{Ir}^{\mathrm{III}} / \mathrm{Ir}^{\mathrm{IV}}$ redox couple with contribution from the $\mathrm{C}^{\wedge} \mathrm{N}$ ligands $(\mathbf{3}$ in Figure $\mathbf{8 b}) \cdot{ }^{19}$ In line with NMR and absorption data, the CV of $\mathbf{3 a}$ contains the superposition of the CVs of $\mathbf{3}$ and ZnTPP. These control experiments show that, as expected, there is no ground-state electronic communication between $\mathbf{3}$ and ZnTPP.

\section{Emission studies.}

Upon photoexcitation into the CT band of the iridium complex $\left(\lambda_{\mathrm{exc}}=360 \mathrm{~nm}\right)$ at a concentration of $3 \times 10^{-5} \mathrm{M}$, a broad and unstructured emission profile is observed for $\mathbf{1}\left(\lambda_{\mathrm{em}}\right.$ $=638 \mathrm{~nm}$, red line in Figure S50a), indicating an emission from a mixed ${ }^{3} \mathrm{MLCT} /{ }^{3} \mathrm{LLCT}$ state. The character of the emissive state was confirmed by the DFT optimization of the lowest triplet excited state $\left(\mathrm{T}_{1}\right.$, (Figure 9)). Incorporation of electron-withdrawing fluorine atoms on the $\mathrm{C}^{\wedge} \mathrm{N}$ ligand induced the expected blue-shift in the emission observed for complexes $2\left(\lambda_{\mathrm{em}}: 565 \mathrm{~nm}\right)$ compared to the fluorine-free congener 1 (red line in Figure S50b). As reported in Table S3, a $\Phi_{\mathrm{PL}}$ of $14 \%\left(\lambda_{\mathrm{exc}}=360 \mathrm{~nm}\right)$ with $\tau_{\mathrm{e}}$ of $300 \mathrm{~ns}$ has been obtained for 1 whereas a higher $\Phi_{\mathrm{PL}}$ of $34 \%\left(\lambda_{\mathrm{exc}}=360 \mathrm{~nm}\right)$ with $\tau_{\mathrm{e}}$ of $993 \mathrm{~ns}$ has been obtained for 2. Upon excitation of ZnTPP into either the Soret or Q bands ( $\lambda_{\mathrm{exc}}=420$ or 550 $\mathrm{nm}$, respectively), a vibronic emission, characteristic of $\mathrm{ZnTPP},{ }^{17}$ is observed between 570 and $740 \mathrm{~nm}$ (light blue line in Figure S50). 



Figure 9. Spin-density distributions (B3LYP/6-31G(d) - ecp-60-mwb for Ir) at the optimized geometry of the lowest triplet excited state of $\mathbf{1}$ and $\mathbf{1 a}$ and $\mathbf{1 b} . \triangle \mathrm{SCF}-\mathrm{DFT}$ emission energies determined at the same level of theory are indicated below the structures. Contour threshold: 0.009 a.u. (1) and 0.005 a.u. (1a and 1b).

In order to investigate the nature of the emission of $\mathbf{1 a}, \mathbf{1 b}, \mathbf{2 a}$ and $\mathbf{2 b}$ and the presence of energy and/or electron transfer between the iridium moiety and ZnTPP, these assemblies were excited into both the ${ }^{1} \mathrm{CT}$ band (centered on the iridium complex, $\lambda_{\text {exc }}=360$ $\mathrm{nm}$ ), and the Soret and Q bands. Unfortunately, the emission of 1 and ZnTPP coincidentally overlap and consequently the study of this system proved challenging (Figure S50a). In contrast, due to the introduction of the fluorine atoms on the $\mathrm{C}^{\wedge} \mathrm{N}$ ligands, the emissions of $\mathbf{2}$ and ZnTPP are better resolved (Figure S50b), which makes this system much more amenable towards the study of electronic communication between the chromophores. ${ }^{31}$ However, at the very low concentrations required for quantifiable steady-state emission experiments, the association between ZnTPP and the iridium complex is almost non-existent, whereas at concentrations higher than $10^{-4} \mathrm{M}$ (above $\mathrm{k}_{\mathrm{d}}$, association $>80 \%$ ), only self-absorption of the emission of complex $\mathbf{2}$ due to the presence of ZnTPP is observed by both emission titration 
experiments and high-time-resolution streak camera measurements (see Figure S66 for emission titrations and Figure S75 and S76 for streak camera studies). The same selfabsorption was also observed for the "non-assembly 3a" (Figure S67).

DFT modeling reveals that for $\mathbf{1 a}$ and $\mathbf{1 b}$ the lowest triplet excited-state is a ${ }^{3} \mathrm{CT}$ state involving the HOMO located on the ZnTPP moiety and the LUMO located on the qpy ligand. They are theoretically located in the NIR region (e.g., at ca. $1250 \mathrm{~nm}$ for 1a). Therefore, these ${ }^{3} \mathrm{CT}$ states are likely not involved in the emission of the assemblies and may play an important role in the non-radiative deactivation pathways of the assemblies. Thus, the emission observed for the assemblies is merely monomer-based and the hypothesis of emission arising from new transitions can be ruled out. The same findings also hold for both 2a and $\mathbf{2 b}$.

The redox potentials combined with the optical data were used to estimate the free energies associated with PeT processes in 1a and 2a following the Rehm-Weller equation (see the ESI for details). ${ }^{32}$ Due to the very similar optoelectronic data obtained for $\mathbf{1 b}$ and $\mathbf{2 b}$, the same results can be readily extended to the 1:2 assemblies. For both for $\mathbf{1 a}$ and $\mathbf{2 a}$, upon photoexcitation of the porphyrin unit, photoinduced electron transfer to the iridium center is found to be exergonic in DCM $\left(\Delta G_{C S}=-0.68 \mathrm{eV}\right)$. At present no evidence of emission quenching due to formation of charge-separated state has been experimentally observed by steady-state and time-resolved spectroscopy. By contrast, due to the higher energy required to extract an electron from the iridium complexes, $\Delta G_{C S}$ for PeT processes, in which $\mathbf{1}$ and $\mathbf{2}$ act as donors and ZnTPP acts as the acceptor, are found to be $+0.38 \mathrm{eV}$ for $1 \mathrm{a}$ and $+0.08 \mathrm{eV}$ for 2a and thus not thermodynamically favorable (for further details see estimation of PeT in the ESI). 


\section{Conclusions.}

We report the synthesis and optoelectronic study of supramolecular assemblies composed of a cationic iridium complex of the form $\left[\operatorname{Ir}\left(\mathrm{C}^{\wedge} \mathrm{N}\right)_{2}(\mathrm{qpy})\right] \mathrm{PF}_{6}$ and $\mathrm{ZnTPP}$, through dynamic and non-covalent interactions between the distal pyridine moieties of the qpy ligands of the iridium complex and zinc. ${ }^{1} \mathrm{H}$ NMR titration experiments reveal equilibrium constants of $8000 \pm 370 \mathrm{M}^{-1}$ for the formation of $1 \mathrm{a}$ from 1 and ZnTPP, and $2000 \pm 190 \mathrm{M}^{-1}$ for the formation of $\mathbf{1 b}$ from 1a and ZnTPP. The structures of the assemblies have been elucidated by X-Ray single-crystal structure analyses. For the assemblies $\mathbf{1 a}, \mathbf{1 b}, \mathbf{2 a}$ and $\mathbf{2 b}$, strong self-absorption of the iridium emissions due to the presence of ZnTPP was observed with no evidence of Förster energy transfer between the units. Furthermore, despite favorable thermodynamics for electron transfer from ZnTPP to iridium, no evidence of the formation of a charge-separated state following electron transfer was observed by steady-state and timeresolved emission spectroscopy.

Acknowledgements. EZ-C acknowledges the University of St Andrews for financial support. We thank Umicore AG for the gift of materials. IDWS acknowledges support from EPSRC (EP/J009016) and the European Research Council (grant 321305). IDWS also acknowledges support from a Royal Society Wolfson research merit award. We thank the EPSRC UK National Mass Spectrometry Facility at Swansea University for analytical services. DJ acknowledges the European Research Council (grant: 278845) and the RFI Lumomat for financial support. This research used resources of (1) the GENCICINES/IDRIS, (2) Centre de Calcul Intensif des Pays de Loire (CCIPL), and (3) a local Troy cluster. 
Supporting information. Experimental section, characterization of precursors, ligands, iridium complexes and supramolecular assemblies; solution NMR investigations of the assemblies; determination of the association constants and displacement assays using DMAP; $\mathrm{X}$-ray crystal structure parameters of $\mathbf{1}, \mathbf{1 a}$ and $\mathbf{1 b}$, and crystal structures of complex $\mathbf{3}$ and ZnTPP-ether; solid-state NMR characterization; absorption and emission studies at different concentrations, emission studies, streak camera studies and electrochemical characterization; computational details, including simulated absorption spectra, representation of the key frontier molecular orbitals; theoretical estimation of photoinduced electron transfer processes; as well as CIF files for 1, 1a and 1b, $\mathbf{3}$ and ZnTPP-ether, CCDC: 1472895-1472899.

\section{References}

(1). (a) R. A. Haycock, A. Yartsev, U. Michelsen, V. Sundström and C. A. Hunter, Angew. Chem. Int. Ed., 2000, 39, 3616-3619; (b) X. Chi, A. J. Guerin, R. A. Haycock, C. A. Hunter and L. D. Sarson, J. Chem. Soc., Chem. Commun., 1995, 2567-2569; (c) Y. Kuramochi, A. Satake, M. Itou, K. Ogawa, Y. Araki, O. Ito and Y. Kobuke, Chemistry, 2008, 14, 2827-2841; (d) Y. Kuramochi, A. S. Sandanayaka, A. Satake, Y. Araki, K. Ogawa, O. Ito and Y. Kobuke, Chemistry, 2009, 15, 2317-2327; (e) J.-M. Lehn, Science, 2002, 295, 2400-2403.

(2). N. Armaroli and V. Balzani, Angew Chem Int Ed Engl, 2007, 46, 52-66.

(3). N. Armaroli and V. Balzani, Chem. Eur. J., 2015, ASAP, DOI: 10.1002/chem.201503580.

(4). (a) A. W. Roszak, T. D. Howard, J. Southall, A. T. Gardiner, C. J. Law, N. W. Isaacs and R. J. Cogdell, Science, 2003, 302, 1969-1972; (b) G. McDermott, S. M. Prince, A. A. Freer, A. M. Hawthornthwaite-Lawless, M. Z. Papiz, R. J. Cogdell and N. W. Isaacs, Nature, 1995, 374, 517-521; (c) S. Bahatyrova, R. N. Frese, C. A. Siebert, J. D. Olsen, K. O. van der Werf, R. van Grondelle, R. A. Niederman, P. A. Bullough, C. Otto and C. N. Hunter, Nature, 2004, 430, 1058-1062.

(5). (a) M. D. Ward, Chem. Soc. Rev., 1997, 26, 365-375; (b) D. Kim and E.-J. Shin, Bull. Korean Chem. Soc., 2003, 24, 1490-1494; (c) J. L. Sessler, C. T. Brown, D. O'Connor, S. L. Springs, R. Wang, M. Sathiosatham and T. Hirose, J. Org. Chem., 1998, 63, 7370-7374.

(6). (a) A. Prodi, M. T. Indelli, C. J. Kleverlaan, E. Alessio and F. Scandola, Coord. Chem. Rev., 2002, 229, 51-58; (b) F. D'Souza, E. Maligaspe, K. Ohkubo, M. E. Zandler, N. K. Subbaiyan and S. Fukuzumi, J. Am. Chem. Soc., 2009, 131, 8787-8797; (c) L. Yu, K. Muthukumaran, I. V. Sazanovich, C. Kirmaier, E. Hindin, J. R. Diers, P. D. Boyle, D. F. 
Bocian, D. Holten and J. S. Lindsey, Inorg. Chem., 2003, 42, 6629-6647; (d) L. Flamigni, G. Marconi, I. M. Dixon, J.-P. Collin and J.-P. Sauvage, J. Phys. Chem. B, 2002, 106, 66636671; (e) F. Ito, Y. Ishibashi, S. R. Khan, H. Miyasaka, K. Kameyama, M. Morisue, A. Satake, K. Ogawa and Y. Kobuke, J. Phys. Chem. A, 2006, 110, 12734-12742; (f) D. LeGourriérec, M. Andersson, J. Davidsson, E. Mukhtar, L. Sun and L. Hammarström, J. Phys. Chem. A, 1999, 103, 557-559; (g) Y. Ishida, T. Shimada and S. Takagi, J. Phys. Chem. C, 2013, 117, 9154-9163; (h) E. Iengo, E. Zangrando, M. Bellini, E. Alessio, A. Prodi, C. Chiorboli and F. Scandola, Inorg. Chem., 2005, 44, 9752-9762; (i) B. Ventura, A. Barbieri, A. Degli Esposti, J. B. Seneclauze and R. Ziessel, Inorg. Chem., 2012, 51, 2832-2840; (j) J. Osío Barcina, N. Herrero-García, F. Cucinotta, L. De Cola, P. Contreras-Carballada, R. M. Williams and A. Guerrero-Martínez, Chem. Eur. J., 2010, 16, 6033-6040.

(7). (a) F. Scandola, C. Chiorboli, A. Prodi, E. Iengo and E. Alessio, Coord. Chem. Rev., 2006, 250, 1471-1496; (b) J. Otsuki, T. Akasaka and K. Araki, Coord. Chem. Rev., 2008, 252, 32-56; (c) A. F. Nogueira, L. F. O. Furtado, A. L. B. Formiga, M. Nakamura, K. Araki and H. E. Toma, Inorg. Chem., 2004, 43, 396-398; (d) D. E. Williams, J. A. Rietman, J. M. Maier, R. Tan, A. B. Greytak, M. D. Smith, J. A. Krause and N. B. Shustova, J. Am. Chem. Soc., 2014, 136, 11886-11889; (e) A. Gabrielsson, F. Hartl, H. Zhang, J. R. Lindsay Smith, M. Towrie, A. Vlček and R. N. Perutz, J. Am. Chem. Soc., 2006, 128, 4253-4266.

(8). A. Harriman, M. Hissler, O. Trompette and R. Ziessel, J. Am. Chem. Soc., 1999, 121, 2516-2525.

(9). (a) J. Henderson and C. P. Kubiak, Inorg Chem, 2014, 53, 11298-11306; (b) M. Murai, M. Sugimoto and M. Akita, Dalton Trans, 2013, 42, 16108-16120; (c) P. Sweigert, Z. Xu, Y. Hong and S. Swavey, Dalton Trans, 2012, 41, 5201-5208; (d) A. M. Soliman, M. Abdelhameed, E. Zysman-Colman and P. D. Harvey, Chem. Commun., 2013, 49, 5544-5546. (10). (a) M. D. Ward and P. R. Raithby, Chem. Soc. Rev., 2013, 42, 1619-1636; (b) A. Satake and Y. Kobuke, Tetrahedron, 2005, 61, 13-41; (c) L. Flamigni, J.-P. Collin and J.-P. Sauvage, Acc. Chem. Res., 2008, 41, 857-871; (d) I. M. Dixon, J.-P. Collin, J.-P. Sauvage, L. Flamigni, S. Encinas and F. Barigelletti, Chem. Soc. Rev., 2000, 29, 385-391.

(11). (a) N. Miyaura and A. Suzuki, Chem. Rev., 1995, 95, 2457-2483; (b) N. Miyaura, T. Yanagi and A. Suzuki, Synth. Commun., 1981, 11, 513-519.

(12). V. N. Kozhevnikov, Y. Zheng, M. Clough, H. A. Al-Attar, G. C. Griffiths, K. Abdullah, S. Raisys, V. Jankus, M. R. Bryce and A. P. Monkman, Chem. Mater., 2013, 25, 2352-2358.

(13). D. Rota Martir, A. K. Bansal, V. Di Mascio, D. B. Cordes, A. F. Henwood, A. M. Z. Slawin, P. C. J. Kamer, L. Martinez-Sarti, A. Pertegas, H. J. Bolink, I. D. W. Samuel and E. Zysman-Colman, Inorganic Chemistry Frontiers, 2016, 3, 218-235.

(14). C. Zhong, C. Duan, F. Huang, H. Wu and Y. Cao, Chem. Mater., 2011, 23, 326-340.

(15). M. Nonoyama, Bull. Chem. Soc. Jpn., 1974, 47, 767-768.

(16). S. Bossmann, A. Shi and M. Pokhrel, Synthesis, 2007, 2007, 505-514.

(17). J. C. Manton, C. Long, J. G. Vos and M. T. Pryce, Dalton Trans, 2014, 43, 3576-3583.

(18). (a) H. Sun, C. Navarro and C. A. Hunter, Org. Biomol. Chem., 2015, 13, 4981-4992; (b) F. D'Souza, S. Gadde, M. E. Zandler, M. Itou, Y. Araki and O. Ito, Chem. Commun., 2004, 2276-2277.

(19). S. Ladouceur, D. Fortin and E. Zysman-Colman, Inorg. Chem., 2010, 49, 5625-5641.

(20). (a) N. M. Shavaleev, G. Xie, S. Varghese, D. B. Cordes, A. M. Z. Slawin, C. Momblona, E. Ortí, H. J. Bolink, I. D. W. Samuel and E. Zysman-Colman, Inorg. Chem., 2015, 54, 5907-5914; (b) R. D. Costa, E. Ortì, H. J. Bolink, S. Graber, S. Schaffner, M. Neuburger, C. E. Housecroft and E. C. Constable, Adv. Funct. Mater., 2009, 19, 3456-3463; (c) A. B. Tamayo, S. Garon, T. Sajoto, P. I. Djurovich, I. M. Tsyba, R. Bau and M. E. Thompson, Inorg. Chem., 2005, 44, 8723-8732. 
(21). (a) P. S. Sobolev, V. P. Andreev and T. A. Ekimova, Russ. J. Gen. Chem., 2014, 84, 1399-1403; (b) A. L. Litvinov, D. V. Konarev, A. Y. Kovalevsky, I. S. Neretin, P. Coppens and R. N. Lyubovskaya, Crystal Growth \& Design, 2005, 5, 1807-1819.

(22). After mixing 1 with 1 equivalent of ZnTPP, the following concentrations are obtained: [1] $=0.00007 \mathrm{M} ;[\mathbf{1 a}]=0.002 \mathrm{M} ;[\mathbf{1 b}]=0.0004 \mathrm{M}$. After mixing $\mathbf{1}$ with 2 equivalent of ZnTPP, the following concentrations are obtained: $[\mathbf{1}]=0.00006 \mathrm{M} ;[\mathbf{1 a}]=0.0006 \mathrm{M} ;[\mathbf{1 b}]=$ $0.0009 \mathrm{M}$.

(23). (a) D. Escudero and W. Thiel, J. Chem. Phys., 2014, 140, 194105; (b) D. Escudero and D. Jacquemin, Dalton Trans., 2015, 44, 8346-8355.

(24). (a) S. Ladouceur and E. Zysman-Colman, Eur. J. Inorg. Chem., 2013, 2013, 2985-3007;

(b) S. Lamansky, P. Djurovich, D. Murphy, F. Abdel-Razzaq, R. Kwong, I. Tsyba, M. Bortz,

B. Mui, R. Bau and M. E. Thompson, Inorg. Chem., 2001, 40, 1704-1711; (c) S. Lamansky, P. Djurovich, D. Murphy, F. Abdel-Razzaq, H.-E. Lee, C. Adachi, P. E. Burrows, S. R. Forrest and M. E. Thompson, J. Am. Chem. Soc., 2001, 123, 4304-4312.

(25). S. Ladouceur, D. Fortin and E. Zysman-Colman, Inorg. Chem., 2011, 50, 11514-11526. (26). (a) P. C. Ray and Z. Sainudeen, J. Phys. Chem. A, 2006, 110, 12342-12347; (b) E. Collini, C. Ferrante and R. Bozio, J. Phys. Chem. C, 2007, 111, 18636-18645.

(27). V. A. Walters, J. C. de Paula, B. Jackson, C. Nutaitis, K. Hall, J. Lind, K. Cardozo, K. Chandran, D. Raible and C. M. Phillips, J. Phys. Chem., 1995, 99, 1166-1171.

(28). C.-W. Huang, K. Yuan Chiu and S.-H. Cheng, Dalton Trans., 2005, 2417-2422.

(29). F. D'Souza, Y.-Y. Hsieh and G. R. Deviprasad, Inorg. Chem., 1996, 35, 5747-5749.

(30). N. G. Connelly and W. E. Geiger, Chem. Rev., 1996, 96, 877-910.

(31). J. Wu, F. Liu, J. Ma, R. J. Silbey and J. Cao, J Chem Phys, 2012, 137, 174111.

(32). (a) G. J. Kavarnos and N. J. Turro, Chem. Rev., 1986, 86, 401-449; (b) S. Doose, H.

Neuweiler and M. Sauer, Chemphyschem, 2009, 10, 1389-1398.

\section{TOC Graphic}

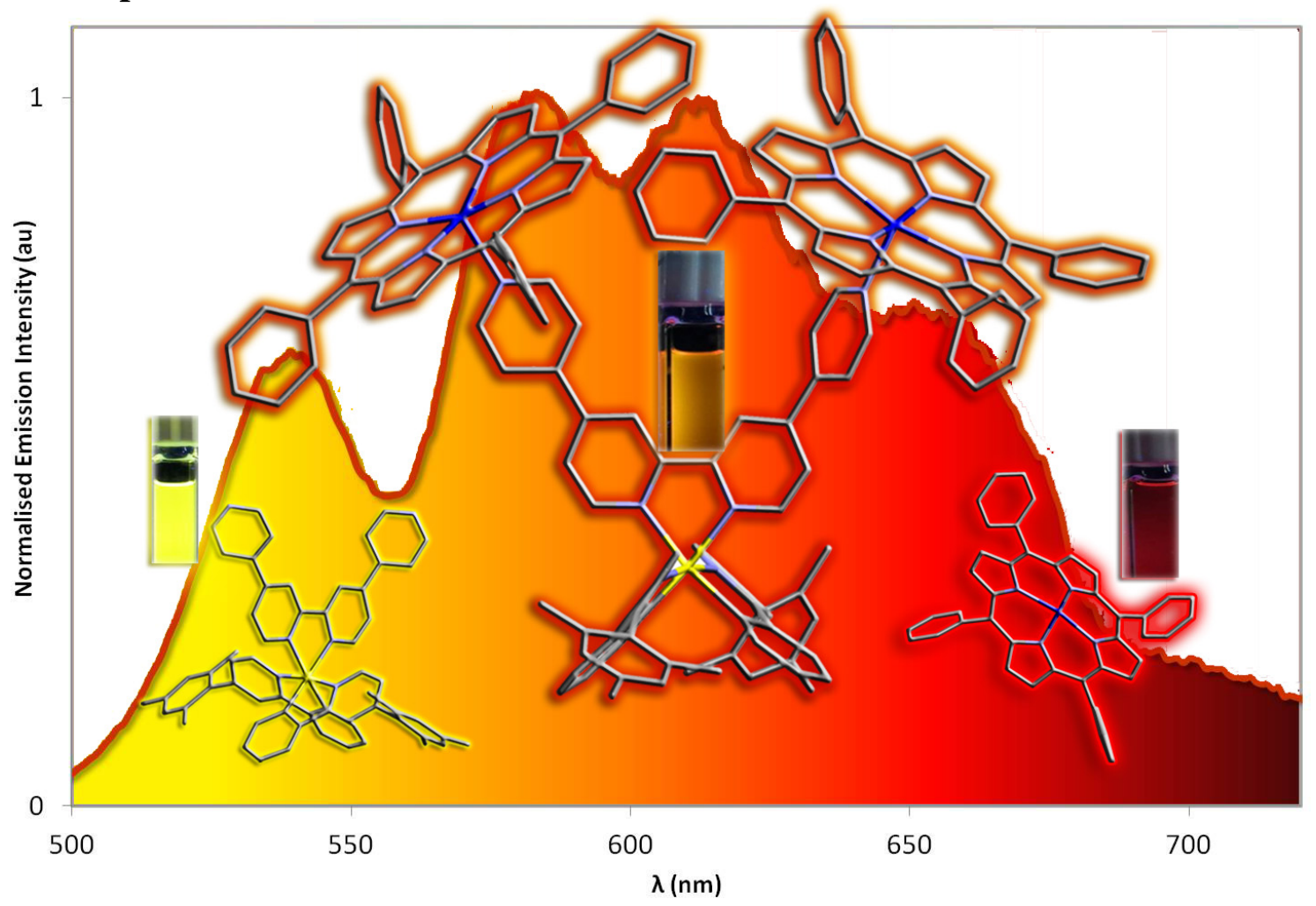

